- Kátia Borgia Barbosa Pagnano - Fabiola Traina

- Tatiana Takahashi - G islaine Borba O liveira

- Marta Soares Rossini - Irene Lorand-M etze

- Afonso Celso Vigorito - Eliana Cristina Martins M iranda

- Cármino Antonio De Souza

\title{
Conventional chemotherapy for acute myeloid leukemia: a Brazilian experience
}

\author{
$H$ ematology and $H$ emotherapy Center, B one M arrow Transplantation Unit, \\ Universidade Estadual de Campinas, Campinas, B razil
}

\section{a bstract}

CONTEXT: Young patients affected by acute myeloid leukemia (AM L) achieve complete remission (CR) using conventional chemotherapy in about $55-85 \%$. However, $30 \%$ of patients fail to achieve CR and the remission duration is often only about 12 months. M ore intensive treatment after $C R$ seems to be necessary in order to maintain $C R$ and obtain a definitive cure. In Brazil, few reports have been published on this important subject.

OBJECTIVE: The aim of this study was to describe a Brazilian experience in the treatment of "de novo" acute myeloid leukemia (AM L) in younger adult patients (age $<60$ years).

DESIGN: Retrospective analysis.

SETING: University Hospital, Hematology and Hemotherapy Center, State University of Campinas, Brazil.

PARTICIPANTS: N ewly diagnosed cases of "de novo" AML in the period from January 1994 to December 1998 were evaluated retrospectively, in relation to response to treatment, overall survival $(O S)$ and disease free survival (DFS). Cases with a cute promyelocytic leukemia (APL) were also included in this analysis.

RESULTS: $O \mathrm{n}$ the basis of an intention to treat, 78 cases of $A M L$, including 17 cases of APL, were evaluated. The overall median followup was 272 days. The complete remission (CR) rate was $63.6 \%$ in the $A M L$ group (excluding $A P L$ ) and $78 \%$ in the APL group. The $5-$ year estimated disease-free survival (DFS) was $80 \%$ for the APL group and $34 \%$ for the $A M L$ group $(P=0.02)$. The 5 -year estimated overall survival (OS) was $52 \%$ for the APL group and $20.5 \%$ for the AML group, respectively $(P=N S)$. Relapse was observed in $12 / 39$ $(30.7 \%)$ patients with $A M L$ and $1 / 11(9 \%)$ with APL

CONCLUSIONS: These results are similar to those reported in the literature. However, relapse and mortality rates remain high, and a search for more aggressive strategies in order to prevent relapse is recommended.

KEY WORDS: Acute myeloid leukemia. Chemotherapy. Bone marrow transplantation. Survival

\section{INTRODUCTION}

During the 1980's and 1990's an increasing majority of patients with AML achieved $C R$ and the proportion of patients remaining in permanent remission also improved. ${ }^{1,2}$ Intensified induction therapy may affect the long term survival without an apparent effect on the initial response rate. ${ }^{3} \mathrm{CR}$ rates in previously untreated patients with de novo AML using High Dose Ara-C (HDAC) have been reported to be $50-80 \%,{ }^{4,5}$

The general trend in the therapeutic strategy has invariably been aimed towards more aggressive treatment administered as soon as CR is achieved. The reason for this has been to provide a maximum of antitumor effect, a so-called consolidation or intensification treatment. ${ }^{6}$

Three intensive consolidation strategies are currently proposed for younger adults with AML in first CR: allogeneic or autologous bone marrow transplantation (BMT) or intensive consolidation chemotherapy. ${ }^{7.8}$ For patients who are younger than 45 , myel oablative treatment with allogeneic BMT, from an identical HLA sibling donor, has become an accepted treatment, when a donor is available. However, allogeneic BMT carries substantial procedural risk related to mortality and morbidity, resulting in a 5year overall survival of around $50 \% .{ }^{8}$ Autologous stem cell transplantation offers the possibility of performing the same myeloablative regimen in patients without a compatible donor and without the risks associated with graft-versus-host-disease (GVHD). ${ }^{7}$

Results from randomized studies comparing 
chemotherapy alone to allogeneic and autologous bone marrow transplantation have become available. ${ }^{7-}$ ${ }^{11}$ Better results are seen in APL, a distinct subtype of $A M L$, in which a balanced reciprocal translocation between chromosomes 15 and 17 results in the union of portions of the promyelocytic leukemia gene with the gene for retinoic acid receptor alpha. The disease typically presents with a life-threatening hemorrhagic diathesis, which worsens by cytotoxic chemotherapy, with early hemorrhagic deaths of about $10-20 \%$. The use of all-trans-retinoic acid (ATRA) followed by anthracycline in the induction therapy of APL has improved the outcome, with the $\mathrm{CR}$ rate reaching more than $90 \%$ and reducing the incidence of relapse. ${ }^{12,13,14}$

The aim of this study was to describe a Brazilian experience in the treatment of adult patients affected by $A M L$, including $A P L$, providing a basis for more intensive approaches in the future.

\section{METHODS}

Patients. Patients under 60 years of age, with previously untreated "denovo" acute myeloid leukemia (AML) diagnosed and treated between 1994 and 1998 at the State University of Campinas were enrolled in this study. The diagnosis was assessed by bone marrow (BM) aspiration showing at least $30 \%$ of blasts, or by a bone marrow biopsy, in the case of associated

\section{Table 1. French-American-British classification of $\mathbf{7 8}$ patients affected by acute myeloid leukemia}

\begin{tabular}{ccc}
\hline & $\mathbf{N}$ & $\%$ \\
\hline M 0 & 2 & 2.5 \\
M 1 & 6 & 7.8 \\
M 2 & 17 & 21.8 \\
M & 17 & 21.8 \\
M 4 & 25 & 32 \\
M 5 & 6 & 7.8 \\
M 6 & 1 & 1.3 \\
M 7 & 0 & 0 \\
not classified* & 4 & 5 \\
Total & 78 & \\
\hline * biphenotypic AML, one case of granulocytic sarcoma.
\end{tabular}

Table 2. Clinical and laboratory characteristics of patients with AML

\begin{tabular}{lll}
\hline & AML group (n=61) & APL group(n=17) \\
\hline median age & $32(14$ to 59$)$ & $33(16$ to 54$) \mathrm{S}$ e $\mathrm{x}$ \\
$(\mathrm{M} / \mathrm{F})$ & $31 / 30$ & $7 / 10$ \\
$\mathrm{Hb}(\mathrm{g} / \mathrm{dl})$ & $8.3(4.5$ to 15$)$ & $8.0(5$ to 12$)$ \\
$\mathrm{W} \mathrm{BC} \times 10^{9} / \mathrm{L}$ & $20(0.4$ to 214$)$ & $3.3(0.7$ to 49$)$ \\
$\%$ blasts peripheral blood & $60.5(0$ to 98$)$ & $15(3$ to 91$) \%$ \\
blasts bone marrow & $76(30$ to 99$)$ & $75.5(38$ to 99$)$ \\
Platelets $\times 10^{9} / \mathrm{L}$ & $42(2$ to 247$)$ & $18(2$ to 146$)$ \\
median follow-up (days) & $261.5(1$ to 1842$)$ & $419(4$ to 1580$)$ \\
\hline AML - acute myeloid leukemia; APL-acute promyelocytic leukemia; M - \\
male; F - female.
\end{tabular}

myelofibrosis. Each case was classified according to the French-American-British (FAB) System. ${ }^{15,16}$ Patients with a previous history of myelodysplasia, myeloproliferative disease and previous chemotherapy or radiotherapy treatment were not included in this study.

L eukemia diagnosis. For the classification we used the procedures recommended by Scott, et al.$^{23}$ We used conventional cytochemistry techniques for the classification of AML: Sudan Black, PAS and unspecific esterase, with and without $\mathrm{NaF}$ inhibition. Cases considered to be Sudan Black negative were studied by flow cytometry with the following antibodies: CD45, CD10/CD19, CD3/DR, CD7/CD33, CD14/CD34, CD13 and myeloperoxidase (MPO). Immunocytochemistry in slides was performed with antibodies to glycophorin, CD41 and CD62 when necessary. APL was classified by morphology. Cytogenetic studies were available for only two APL patients: one presented t (15.17) and PCR positive for the translocation PML/RAR $\alpha$. The other one had variant microgranular morphology and had a normal karyotype.

Treatment. The induction treatment consisted of 1 or 2 cycles of TAD-9, as described elsewhere. ${ }^{1}$ Bone marrow aspiration was performed between the $14^{\text {th }}$ and $21^{\text {st }}$ day after the last day of chemotherapy. Patients who did not achieve complete remission (CR) after two cycles of TAD-9 were treated with a salvage regimen, named MEC. ${ }^{17}$ Patients who achieved CR were submitted to two consecutive consolidation cycles, one with HDAC plus daunorubicin (ARAC $2 \mathrm{~g} / \mathrm{m}^{2}$ IV twice a day on days $1-4$ and daunorubicin $45 \mathrm{mg} / \mathrm{m}^{2}$ on days 5-7), followed by one cycle of TAD-7, as described elsewhere. ${ }^{1}$ After these 2 cycles, patients were submitted to maintenance treatment for 24 months, with monthly cycles of ARAC $100 \mathrm{mg} / \mathrm{m}^{2} \mathrm{SC}$ twice a day on days 1-5, alternating monthly cyclophosphamide, daunorubicin and thioguanine. ${ }^{2}$

A search for an HLA identical donor was performed for all patients under 50 years of age, and allogeneic BMT was proposed to patients with an HLAidentical sibling donor available (except to APL patients).

Patients affected by APL received an ATRAcontaining regimen as induction treatment, according to initial leukometry. Patients with WBC $=5 \times 10^{9} / \mathrm{L}$ were treated with ATRA. Patients with WBC between $6 \times 10^{9} / \mathrm{L}$ and $10 \times 10^{9} / \mathrm{L}$ were treated with ATRA and TAD9 and patients with $\mathrm{WBC}>10 \times 10^{9} / \mathrm{L}$ at diagnosis received only conventional chemotherapy as induction treatment (TAD-9). One patient was treated with ATRA and daunorubicin as induction. ATRA was 
interrupted and chemotherapy added if patients presented ATRA syndrome and/or leukocytosis. The post remission therapy for APL patients was the same used for the other AML subtypes. No allogeneic BMT was performed in APL patients during the first CR.

Response criteria. CR was defined as more than $1.0 \times 10^{\circ} / \mathrm{L}$ granulocytes and more than $100 \times 10^{\circ} / \mathrm{L}$ platelets in peripheral blood, and normocellular BM containing less than $5 \%$ of blasts cells. Patients who did not fulfill the above criteria were considered nonresponders.

Statistical methods. Analysis was based on status of the patients on April $20^{\text {th }} 1999$, based on the last follow-up. Overall survival (OS) was defined from the date of diagnosis and beginning of chemotherapy until death or last follow-up. Disease free survival (DFS) was calculated from the date of first complete remission until the date of death, first relapse or last follow-up in continuous CR. Survival curves were calculated by the Kaplan-Meier method and differences between the curves were analyzed with the log-rank test. ${ }^{18}$ The patients were divided into the $A M L$ group $(n=61)$ and APL group ( $n=17)$. The comparison between WBC number on diagnosis was based on descriptive analysis using the Mann-Whitney test.

\section{RESULTS}

Between January 1994 and December 1998, 87 patients with age below 60 years old were diagnosed as $A M L$ in our hospital. However, nine patients were not evaluated because of early death before starting chemotherapy. Among the 78 evaluated patients, 61 (78.2\%) patients were classified as AML group (nonAPL) and $17(21.8 \%)$ were classified as APL. In the AML group, 31 patients were males and 30 females and the median age was 32 years (14-59). In the APL group, 7 patients were males and 10 females, with a median age of 33 years (16-54). The median number of white blood cells (WBC) at diagnosis was $20 \times 10^{9} / \mathrm{L}(0.4-$ 214) for the AML group and $3.3 \times 10^{\circ} / \mathrm{L}(0.7-49)$ for the APL group $(P=0.004)$ (Table 1). The clinical and laboratory characteristics are shown in Table 1 . The most common $\mathrm{FAB}$ subtypes were $\mathrm{M} 4, \mathrm{M} 2$ and $\mathrm{M} 3$ (32\%, $21.8 \%$ and $21.8 \%$, respectively) (Table 2 ). During the analysis period, no cases of M 7 subtypes were diagnosed. The overall median follow-up was 254 days (1-1842) and 540 days (4-1580) for the AML and APL groups, respectively.

Response At the end of our observation, 33/78 patients (42.3\%) were alive; 32 (41\%) in CR and 1 (1.2\%) with refractory disease after relapse; $45 / 78$ (57.6\%) patients died. AM L group: 30 out of 61 (49\%) patients reached CR with one cycle of TAD-9. Thirteen out of 61 did not achieved CR using one cycle of TAD-9, and 5 of them (8.1\%) achieved CR after the second cycle of TAD9. Three patients (4.9\%) achieved CR after salvage chemotherapy with MEC (2 patients) or HDAC (1 patient). One patient (1.6\%) received as an induction treatment low dose Ara- $C$ due to poor performance status at diagnosis and achieved CR. A total of 39 patients achieved CR (63.6\%). Two patients were submitted to allogeneic bone marrow transplantation, while in first CR and remained in CR. Four patients died during consolidation therapy while in CR. Twelve out of 35 (34.2\%) patients relapsed, after a median time of 287.5 days (50-1265) from first CR (AML group). APL patients: Seven patients with $\mathrm{WBC} \leq 5 \times 10^{\circ} / \mathrm{L}$ were treated initially with ATRA. TAD-9 was associated in 7 cases with a rise in WBC and/or ATRA syndrome. Eleven out of 14 (78\%) patients who used an ATRA-containing regimen achieved CR. Three patients were treated with conventional chemotherapy alone and died during induction. One out of 11 (9\%) relapsed, after 22 months

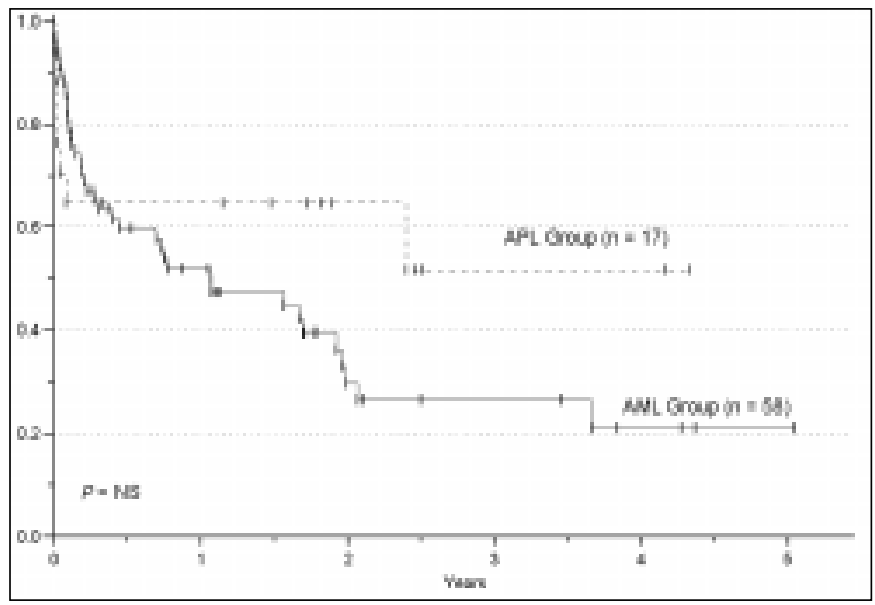

Figure 1. Overall survival in patients affected by AML.

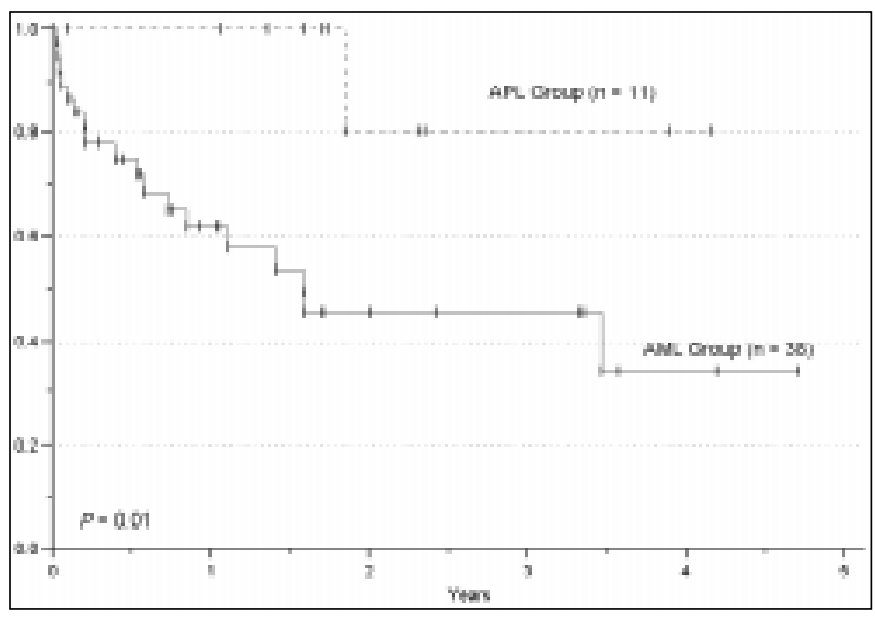

Figure 2. Disease free survival in patients affected by AML. 
in $\mathrm{CR}$, during maintenance treatment.

Survival. The median survival for alive patients was 409 days (67-1842) for the AML (non-APL) group $(n=22)$ and 677 days (118-1580) for the APL group $(n=10)$. The estimated OS for all patients (AML and APL groups) was $27 \%$ over 5 years. The 5 -year estimated OS was $20.5 \%$ and $52 \%$ for AML and APL groups, respectively ( $P=N S$ ). However, the 5 -year estimated DFS was significantly higher in the APL $(80 \%)$ compared to the AML group (34\%) $(P=0.01)$. The overall survival and disease free survival curves for the two groups of patients are shown in Figures 1 and 2, respectively.

Causes of death. AML group: 21 out of 61 (34.5\%) patients died during induction treatment. 13 out of 21 (61.9\%) died due to infection, 2 out of 21 (9.5\%) due to CNS bleeding, 1 out of 21 (4.8\%) due to leukostasis, 1 out of 21 due to acute GVHD, and 4 out of 21 (19\%) due to unknown causes. After consolidation therapy, 4 out of 39 patients $(10.2 \%)$ died during the aplastic phase, due to infection; 3 of them after the first cycle of consolidation (HDAC) and one after the second cycle of consolidation (TAD-7). Eleven out of 35 patients (31.4\%) died after relapse. One out of 11 (9\%) patients died of bleeding before receiving reinduction treatment. Nine out of 11 (82\%) died due to infection, after reinduction chemotherapy. One out of 11 (9\%) was submitted to allogeneic BMT and died due to progressive disease and central nervous system bleeding. None of the relapsed patients achieved CR using salvage therapy. No patients died during maintenance treatment, while in CR. APL group: There were 7 deaths in this group. Three out of 7 (44\%) patients died during TAD-9 induction, two due to disseminated intravascular coagulation (DIC) and one due to infection. Among the patients treated with an ATRAcontaining regimen, 2 out of 7 (28\%) patients died due to ATRA syndrome and one out of $7(14 \%)$ due to infection. One of the 7 (14\%) patients had a late relapse, 22 months after starting $C R$ and died during the aplastic phase post-reinduction therapy, due to infection.

\section{DISCUSSION}

In this retrospective study, we analyzed the results of conventional treatment for patients with $A M L$, age $<60$ years, treated at the University of Campinas. There are few Brazilian studies published concerning results of treatment in AML. ${ }^{19}$ For this age group, there are many reports referring to $C R$ rates between $55 \%$ to $85 \%$, with prolonged DFS, and cures in about $25 \%-30 \%{ }^{4}$

We used TAD- 9 as induction therapy. The CR rate after the $1^{\text {st }}$ cycle was $49 \%$. The second cycle of TAD-9 brought little improvement to the overall CR (8.1\%). In addition, $4.9 \%$ of patients achieved $C R$ with salvage regimens. The overall CR rate was $63.6 \%$, similar to those reported in the literature. ${ }^{2,45}$ With standard induction regimens ( 3 days of anthracycline and 7 days of cytarabine), approximately $30 \%$ of patients still fail to achieve $\mathrm{CR}$ and the remission duration is often around 12 months.

HDAC has been successfully used in a number of combinations in relapsed patients and as post-remission or consolidation therapy. ${ }^{9,10,11}$ We used one cycle of HDAC for consolidation and did not observe high toxicity and mortality. Thus, this regimen was demonstrated to be feasible in our patients. Although many different schedules have been used, including consolidation with or without prolonged maintenance, about $25-30 \%$ of patients will remain in CR for 5 years. However, the maintenance of remission is still a challenge. We observed relapse in $34.7 \%$ of the AML group, half of them occurring during the first year post-remission. Our maintenance program was not able to sustain $C R$ in a large number of patients. The 5-year estimated overall survival for the AML group was $20.5 \%$, similar to that reported in the literature. ${ }^{2,4,5}$

Recently, new approaches have been proposed to intensify AML treatment, with the purpose of decreasing relapse incidence, leading to a better $O S$ and DFS. The first large randomized study comparing allogeneic BMT, autologous BMT and intensive consolidation with HDARAC was published by the EORTC and GIMEMA groups. ${ }^{20}$ In this study, BMT resulted in a better DFS than conventional chemotherapy. In the GOELAM study, the 3 groups presented similar results. However, this group used higher doses of ARAC and idarubicin instead of daunorubicin. In this study only $32 \%$ of patients in CR could be randomized between autologous BMT and consolidation with chemotherapy. Moreover, allogeneic BMT was performed without previous intensive consolidation, resulting in a large number of relapses after bone marrow transplantation. The MRC AML 10 trial study showed a better OS and fewer relapses after 4 cycles of chemotherapy followed by autologous BMT. However, in this trial HDARAC was not used. Based on this study, 3 prognostic groups were described according to cytogenetics, FAB classification and response to the first cycle of induction. ${ }^{21}$ The group with favorable prognosis consisted of patients with APL or favorable karyotype (inv 16, t(15-17), t(8-21); 
the standard risk group (neither good nor poor) and the poor risk group were those with adverse karyotype or $>15 \%$ of blasts after the first course of induction. However, except for APL, there is still no consensus in the literature for differentiating $A M L$ treatment according to cytogenetic characteristics. In our study, it was not possible to evaluate cytogenetics in most of the cases, so we could not stratify the patients into risk categories according to this criterion.

The treatment of the APL group using chemotherapy alone was shown to be inadequate, and high rates of mortality due to DIC were observed. The use of all-trans-retinoic acid (ATRA) followed by anthracycline, in the induction therapy of APL, has improved the CR rate to greater than $90 \%$ and reduced the incidence of relapse. ${ }^{12,13,14}$ The addition of ATRA to chemotherapy during induction of APL has brought a great improvement in terms of CR and DFS, also in our patients. DFS was longer in APL (80\%) than in the $A M L$ (non-APL) group (34\%) ( $P=0.02)$. The difference in terms of OS between the 2 groups was not significant, probably due to the small number of APL patients enrolled. Once CR was achieved, relapse was a rare event in this group. We did not observe the high induction mortality rates described by Pulcheri, et al. ${ }^{19}$ Except for APL, allogeneic bone marrow transplantation from an HLA sibling donor is the treatment of choice, despite the transplant-related morbidity and mortality. In our study, patients transplanted in the first CR had better results than those with refractory disease. However, few patients have an available donor. More intensive chemotherapy followed by autologous BMT, or more intensive consolidation, should probably reduce the relapse risk and prolong overall survival.

We may therefore conclude that the overall results achieved at our Institution represent what is expected in the literature for conventional chemotherapy in AML and APL.

Based on this previous experience, we are introducing a new prospective approach to AML treatment: intensification of consolidation with a second HDAC, instead of TAD-7, and a randomized study comparing autologous bone marrow transplantation versus maintenance treatment, for young patients who do not have identical sibling HLA donors available. With this novel strategy, we expect to offer a better chance of cure for these patients.

\section{REFERENCES}

1. Buchner T, Urbanitz D, Hiddemann W, et al. Intensified induction and consolidation with or without maintenance chemotherapy for acute myeloid leukemia (AML): two multicenter studies of the German $A M L$ Cooperative Group. J Clin Oncol 1985;3(12):583-9.

2. Buchner T, Heddemann W, Worman B, et al. Double induction strategy for acute myeloid leukemia: the effect of High-Dose cytarabine with mitoxantrone instead of standard-dose cytarabine with daunorubicin and 6-thioguanine: a randomized trial by the German AML Cooperative Group. Blood 1999;93(12):4116-24.

3. Rowe JM, Tallman MS. Intensifying induction therapy in acute myeloid leukemia: has a new standard of care emerged? Blood 1997;90(6):2121-6

4. Weick J, Kopecky KJ, Appelbaum FR, et al. A randomized investigation of high-dose versus standard-dose cytosine arabinoside with daunorubicin in patients with previously untreated acute myeloid leukemia: a Southwest Oncology Group Study. Blood 1996;88(8):2841-51.

5. Bishop JF, Matthews J, Young GA, et al. A randomized study of highdose cytarabine in induction in acute myeloid leukemia. Blood 1996:87(5):1710-7.
6. Gorin NC. Autologous stem cell transplantation in acute myelocytic leukemia. Blood 1998;92(4):1073-90.

7. Harousseau, JL, Cahn JY, Pignon B, et al. Comparison of autologous bone marrow transplantation and intensive chemotherapy as postremission therapy in adult acute myeloid leukemia (GOELAM). Blood 1997;90(8):2978-86.

8. Burnett AK, Goldstone AH, Stevens RMF, et al. For the UK Medical Research Council Adult and Children's Leukemia Working Parties. Randomized comparison of addition of autologous bone-marrow transplantation to intensive chemotherapy for acute myeloid leukemia in first remission: results of MRC AML 10 trial. Lancet 1998;351:700-8.

9. Champlin $\mathrm{R}, \mathrm{Ho} \mathrm{W}$, Winston $\mathrm{D}$, et al. Treatment of adults with acute myeloid leukemia: prospective evaluation of high dose cytarabine in consolidation chemotherapy and with bone marrow transplantation. Semin Oncol 1987;14:1

10. Mayer RJ, Schiffer CA, Peterson BA, et al. Intensive post-remission therapy in adults with acute non-lymphocytic leukemia using various dose schedules of Ara-C: a progress report from CALGB. Semin Oncol 1987;14(2):25-31. 
11. Brito-Babapulle F, Catovsky D, Newland AC, Goldman JM, Galton DAG Treatment of acute myeloid leukemia with intermediate-dose cytarabine and mitoxantrone. Semin Oncol 1987;14(2):51-2.

12. Barbui T, Finazzi G, Falanga A. The impact of all-trans-retinoic acid on the coagulopathy of acute promyelocytic leukemia. Blood 1998:91(9):3093-102

13. Tallman MS, Andersen JW, Schiffer CA, et al. All-trans-retinoic acid in acute promyelocytic leukemia. New Engl J Med 1997;337(15):1021-8.

14. De Botton S, Dombret $H$, Sanz M, et al. Incidence, clinical features and outcome of all-trans-retinoic acid syndrome in 413 cases of newly diagnosed acute promyelocytic leukemia. Blood 1998;92(8):2712-8.

15. Benett JM, Catovsky D, Daniel MT, et al. Proposals for the classification of the acute leukemias. Br J Haematol 1976;33(4):451-8.

16. Benett JM, Catovsky D, Daniel MT, et al. Proposed revised criteria for the classification of acute myeloid leukemia. Ann Intern Med 1985;103(4):620-5

17. Amadori S, Arcese W, Isacchi G, et al. Mitoxantrone, etoposide and intermediate-dose cytarabine: an effective and tolerable regimen for the treatment of refractory acute myeloid leukemia. J Clin Oncol

\section{1;9(7):1210-4.}

18. Kaplan EL, Meir P. Non-parametric estimation from incomplete observation. J Am Stat Assoc 1958;53:457.

19. Pulcheri W., Spector N., Nucci M, de Morais JC, Pimenta G, de Oliveira $\mathrm{HP}$. The treatment of acute myeloid leukemia in Brazil: progress and obstacles. Haematologica 1995;80(2):130-5.

20. Zittoun RA, Mandelli F, Willemze R, et al. Autologous or allogeneic bone marrow transplantation compared with intensive chemotherapy in acute myelogenous leukemia. New Engl J Med 1995;322:217

21. Wheatley K, Burnett AK, Goldstone AH, et al. A simple, robust, validated and highly predictive index for the determination of riskdirected therapy in acute myeloid leukemia derived from the MRC AML 10 trial. Br J Haematol 1999;107:69-79.

22. Torresan M, Barbosa KB, Souza CA, Lorand-Metze I. Comparação entre quimioterapia e ATRA no tratamento de indução da leucemia promielocítica. Boletim da Sociedade Brasileira de Hematologia e Hemoterapia 1998;XX:111.

23. Scott CS, Den Ottolander GJ, Swirsky D, et al. Recommended procedures for the classification of acute leukemias. Leukemia and Lymphoma 1995;18(Suppl1):1-12.

\section{publishing in formation}

CONTEXTO: Pacientes adultos com diagnóstico de leucemia mielóide aguda (LMA) obtém remissão completa (RC) com quimioterapia convencional em cerca de $55-85 \%$ dos casos, e a sua duração é de aproximadamente 12 meses. Cerca de $30 \%$ dos pacientes não atingem a RC. Para manter a RC e obter cura definitiva parece ser necessário intensificar o tratamento após a RC. No Brasil, há um pequeno número de artigos publicados a esse respeito.

OBJETIVO: Descrever a experiência brasileira no tratamento de leucemia mielóide aguda "de novo" em jovens e adultos com idade inferior a 60 anos.

TIPO DE ESTUDO: A nálise retrospectiva.

LOCAL: Hospital das Clínicas e Hemocentro da Universidade Estadual de Campinas.

PARTICIPANTES: Foram estudados, retrospectivamente, casos novos de LMA entre 1994 e 1998, com relação à resposta ao tratamento de quimioterapia, sobrevida global e sobrevivência livre de doença.

RESULTADOS: Entraram no estudo 78 pacientes de LM A, incluindo 17 casos de leucemia promielocítica (LPM). A média de seguimento foi de 272 dias. A taxa de RC foi de $63,6 \%$ nos pacientes com LM A excluindo-se os pacientes com LPM, e $78 \%$ nos pacientes com LPM. A sobrevida livre de doença em 5 anos foi de $80 \%$ nos pacientes com LPM e $34 \%$ para os pacientes com LM A $(P=0,01)$. A sobrevida global foi de $52 \%$ e $20,5 \%$ para os pacientes com LPM e LMA respectivamente $(P=N$ S). Recidiva foi observada em $12 / 39(30,7 \%)$ dos pacientes com LMA e $1 / 11$ (9\%) na LPM.

CONCLUSÕES: Esses resultados são semelhantes aos encontrados na literatura, entretanto, o número de recidivas e a mortalidade mantém-se alta, recomendando-se pesquisa de estratégias mais agressivas para prevenir recidivas.

PALAVRAS-CHAVE: Leucemia mielóide aguda. Q uimioterapia. Transplante de medula óssea. Sobrevida.
Kátia Borgia Barbosa Pagnano, MD. Hematology and Hemotherapy Center, Universidade Estadual de Campinas, Campinas, São Paulo, Brazil. Fabiola Traina, MD. Hematology and Hemotherapy, Universidade Estadual de Campinas, Campinas, São Paulo, Brazil.

Tatiana Takahashi, MD. Hematology and Hemotherapy Center, Universidade Estadual de Campinas, Campinas, São Paulo, Brazil.

Gislaine Borba Oliveira, MD. Hematology and Hemotherapy Center,

Universidade Estadual de Campinas, Campinas, São Paulo, Brazil.

Marta Soares Rossini, MD. Hematology and Hemotherapy Center,

Universidade Estadual de Campinas, Campinas, São Paulo, Brazil. Irene Lorand-Metze, PhD. Hematology and Hemotherapy Center, Universidade Estadual de Campinas, Campinas, São Paulo, Brazil. Afonso Celso Vigorito, PhD. Director of the Bone Marrow Transplantation Unit, Hematology and Hemotherapy Center, Universidade Estadual de Campinas, Campinas, São Paulo, Brazil.

Eliana Cristina Martins Miranda. Biostatistician, Bone Marrow Transplantation Unit, Hematology and Hemotherapy Center, Universidade Estadual de Campinas, Campinas, São Paulo, Brazil.

Cármino Antonio De Souza, PhD. Director of the Hematology and Hemotherapy Division, Hematology and Hemotherapy Center, Universidade Estadual de Campinas, Campinas, São Paulo, Brazil.

Sources of funding: Not declared

Conflict interest: Not declared

Last received: $14 \mathrm{March} 2000$

Accepted: 02 May 2000

Address for correspondence

Cármino Antonio De Souza

Universidade Estadual de Campinas

Centro de Hematologia e Hemoterapia, TMO

Cidade Universitária "Zeferino Vaz"

PO Box - 6198

Campinas/SP - Brasil - CEP 13081-970

E-mail: carmino@obelix.unicamp.br 